\title{
Editorial
}

\section{Crime prevention efforts: Victims or perpetrators?}

Danger to the well-being and health of a person can result from the actions of others in two kinds of situations. First, danger can stem from premeditated, hostile actions by others. Criminals are sources of such danger. Second, it can result from the inadvertent but also injurious actions of others. Drunk drivers illustrate that kind of danger. In both situations efforts to prevent danger can be directed at the potential victims. Preventive efforts can also be aimed at the perpetrators. If preventive efforts fail, efforts to minimize the effects of hostile or inadvertent hazards can also be directed to these two populations.

Most community prevention efforts are directed at potential victims of deliberate crimes. For example, police departments in high-crime regions often offer lectures, films, discussions, demonstrations, even training sessions, to increase the awareness of potential rape victims to help them prevent such events and to cope with them should an attempt occur.

For nondeliberate interpersonal hazards, such as automobile driving in heavy traffic, there are few continuing preventive efforts. Training for preventive methods and attitudes is, of course, included in driver education courses. These are taken once, when a driver first learns. They may also be included in the simple written tests a driver takes when he renews his driver's license.

Table 1 suggests that investment in efforts to prevent non-deliberate hazards may yield a higher return than investment in efforts to prevent deliberately caused dangers. The former are more frequent. The potential victims and perpetrators are more reachable. Their behavior may be more

North-Holland Publishing Company

Human Systems Management 3 (1982) 225-226
Table 1

Expected payoff from various preventive efforts

\begin{tabular}{lll}
\hline Type of hazard & Aimed at & \\
\cline { 2 - 3 } & Potential victims & Potential perpetrators \\
\hline Deliberate & Very modest & Modest \\
Inadvertent & Quite high & Very high \\
\hline
\end{tabular}

changeable. Special low-cost programs to make potential victims of traffic accidents more aware of the most frequent causes, and to train them to be more attentive to them, could go far to reduce that hazard.

The table also suggests that efforts expended to reach potential perpetrators of either deliberate or non-deliberate hazards could have a greater payoff than efforts directed at the potential victims. Interviews with convicted rapists and other deviants conducted at times that they are in control, suggest that they would welcome help to prevent them from losing control. Many may have a hidden wish to be under custodial care, to be deprived of the opportunity for socio-pathological behavior that often lowers their self-esteem, which is already low. Similarly, many potential perpetrators of traffic accidents, such as alcoholics who drive, may be receptive to any source of effective preventive help.

If the judgments in the table are correct, then most preventive resources should be allocated for efforts directed at such non-deliberate potential perpetrators. This is not to suggest a diversion or non-allocation of resources to the other three groups. Programs directed at potential victims of rape, theft, homicide, etc. should certainly be continued and improved. The fraction of potential 
victims who take advantage of these excellent programs is, however, miniscule.

It is important to allocate resources to the development of effective preventive programs prior to the administration of such programs on a large scale. Support for such development should come from novel institutional arrangements involving talents, facilities and funds from community or citizen participants, from local as well as higher levels of government, from local industries, private foundations, and universities. The control of such hazards constitutes an important and pressing social task, facing nearly every community. It is a challenge to human systems management.

Manfred KOCHEN University of Michigan 